\title{
A MATEMATIZAÇÃO DA VIDA: UMA ANÁLISE DAS PRODUÇÕES CIENTÍFICAS DO CAMPO DA EDUCAÇÃO FÍSICA ACERCA DE PESSOAS NA MEIA IDADE
}

\author{
Priscilla de Cesaro Antunes \\ Universidade Federal de Goiás, Goiânia, Goiás, Brasil \\ Ana Márcia Silva \\ Universidade Federal de Goiás, Goiânia, Goiás, Brasil \\ Tadeu João Ribeiro Baptista \\ Universidade Federal de Goiás, Goiânia, Goiás, Brasil
}

\begin{abstract}
Resumo
Objetivamos analisar as organizações metodológicas que estruturam as investigações da Educação Física produzidas nos Programas de Pós-Graduação Stricto Sensu com pessoas na meia idade e suas implicações na produção do conhecimento face à realidade social concreta. Analisamos os dados de duas teses e dezessete dissertações com base no modelo quadripolar. Identificamos que dezoito pesquisas aproximaram-se da tendência epistemológica empírico-analítica e uma do referencial crítico-dialético. As questões de método enfatizaram a quantificação das informações referentes à vida dos sujeitos, desprezando explicações de ordem mais qualitativa, no âmbito social ou subjetivo, o que por vezes distanciou os estudos do plano do real, no sentido de um potencial impacto social significativo.

Palavras-chave: Educação Física e Treinamento. Meia-idade. Atividade Física. Relatório de Pesquisa.
\end{abstract}

\section{Introdução}

$\mathrm{O}$ debate sobre a produção do conhecimento na Educação Física não é novo. Existem referências de destaque nessa temática no campo (SILVA, 1997; 1990), as quais se debruçaram sobre o fazer científico. Depois desses, vários estudos buscaram refletir e avaliar as obras constituídas em Programas Stricto Sensu em Educação Física no Brasil, a partir de recortes diferenciados, como são os casos de Sacardo (2013), Frizzo (2010), Lemos (2009), Feron e Silva (2007), Molina Neto et al. (2006), Nóbrega et al. (2003), Bankoff et al. (2003), Ludorf (2002), Brandão (2000) entre outros, nos quais é possível identificar a preocupação com os aspectos epistemológicos, me- 
todológicos, bibliométricos, etc., permitindo acompanhar o movimento da apreensão da realidade pela Educação Física.

Voltar o olhar para os conhecimentos produzidos no âmbito acadêmico parece ser uma maneira interessante de compreender o que temos sido enquanto campo científico e quais compromissos temos assumido perante a sociedade. A Educação Física tem construído seus saberes no diálogo com diversos campos de conhecimento, processo que culmina em diferentes formas de pensar/fazer pesquisa e intervenção.

As preocupações com a produção do conhecimento e seu impacto social foram sinalizadas recentemente em editorial da Revista The Lancet (2013), o qual afirmou que $85 \%$ das pesquisas médicas desperdiçam recursos ou são ineficientes, em quatro aspectos: falta de relevância para médicos e pacientes, inadequação do escopo e dos métodos, dificuldade de acesso aos resultados e restrições relacionadas à imparcialidade e à significância clínica, evidenciando a necessidade de uma reflexão crítica.

Este estudo apresenta como objetivo analisar as organizações metodológicas que estruturam as investigações desenvolvidas nos Programas de Pós-Graduação Stricto Sensu em Educação Física acerca de pessoas na meia idade e suas implicações na produção do conhecimento face à realidade social concreta.

Para alcançar o objetivo proposto, apresentamos inicialmente o recorte metodológico adotado. No segundo momento, apresentamos os principais resultados em diálogo com a literatura, dando certa ênfase às ideias de Horkheimer $(2002 ; 1990)$, cujas obras nos ajudam a entender os caminhos da ciência. Assim, consideramos que os dados empíricos não se distanciam da compreensão teórica do objeto investigado.

\section{Metodologia:}

Realizamos uma análise documental sistemática da produção científica sobre meia idade disponível on line e desenvolvida nos Programas de Pós-Graduação Stricto Sensu em Educação Física no Brasil.

Selecionamos o material empírico a partir da faixa etária dos sujeitos das pesquisas: todos deveriam ter entre 40 e 60 anos. Embora este critério seja insuficiente, mostrou-se como mais viável para analisar o fenômeno da meia idade, em virtude da imprecisão conceitual 
que parece caracterizar a produção sobre o tema, talvez motivada pela carência de reflexões sobre esse momento da vida ${ }^{1}$.

Foi necessária certa flexibilização quando o estudo enfocava a meia idade e parte da amostra não estava dentro do limite etário estipulado. A seleção final contou com padrões etários entre 38 e 65 anos, uma ampliação que por si só constitui-se como um dado de reflexão acerca da produção do conhecimento sobre meia idade.

Recuperamos 28 teses e dissertações, nas quais observamos que um tipo de objetivo se destacou, qual seja estudos que visaram analisar/avaliar/comparar/identificar/observar os efeitos de programas de exercícios sobre determinados aspectos da vida. Ao final, foram analisadas duas teses e 17 dissertações, $70 \%$ da produção científica identificada inicialmente.

Sistematizamos os dados com base no modelo quadripolar ${ }^{2}$ (pólo epistemológico, teórico, morfológico e técnico) proposto por Bruyne, Herman e Schoutheete (1991) e Lessard-Hébert, Goyette e Boutin (2005). Segundo Bruyne, Herman e Schoutheete (1991, p.34), a articulação dos pólos "determina um espaço no qual a pesquisa se apresenta como apanhada num campo de forças, submetida a determinados fluxos, a determinadas exigências internas".

No pólo técnico levantamos o tipo de pesquisa, as fontes ou amostras, instrumentos de coleta e análise dos dados. No morfológico identificamos as formas de aproximação ao objeto, de exposição, causação e objetivação. No teórico registramos o referencial teórico do trabalho, as principais temáticas, as propostas e críticas apresentadas. No epistemológico indicamos como se apresentam as pesquisas, a partir das informações dos pólos anteriores, além dos critérios de validação científica e os conceitos de ciência.

Adotamos uma análise de perspectiva quanti-qualitativa, a qual indica que "centralizar a pesquisa em um problema convida a conciliar

1-Observa-se que o tema da meia idade constitui-se como uma lacuna, como indicaram Sousa (2004; 2008), Oliveira (2004) e Domingues (2002) referindo-se às Ciências Humanas e Sociais, e Santos e Knijnik (2006), Duarte, Santos e Gonçalves (2002) e Gonçalves, Duarte e Santos (2001), no âmbito dos estudos em Educação Física.

2-Esse modelo estabelece relação com o "esquema paradigmático" de Gamboa (2007), formado por seis níveis: nível técnico, nível metodológico, nível teórico, nível epistemológico, pressupostos gnosiológicos e pressupostos ontológicos. 
abordagens preocupadas com a complexidade do real, sem perder o contato com os aportes anteriores" (LAVILLE; DIONNE, 1999, p.43). Ao construirmos a análise a partir de uma perspectiva dialética, o movimento reflexivo foi se estabelecendo entre o referencial teórico e a empiria, mas também, internamente à própria lógica das pesquisas que constituíram o material empírico.

\section{Apresentação e análise dos resultados:}

O conjunto da produção apresentou a forte tendência em estudar os efeitos de programas de intervenção sobre determinados aspectos da vida. Identificamos quatro tendências de pesquisa, conforme a tabela abaixo:

Tabela 1: Relação entre as tendências de análise, variáveis e frequências identificadas na pesquisa

\begin{tabular}{|c|l|c|}
\hline $\begin{array}{c}\text { Tendência } \\
\text { de Análise }\end{array}$ & \multicolumn{1}{|c|}{ Tipo de Variáveis } & Frequência \\
\hline a & Somente variáveis fisicas dos participantes & 13 \\
\hline b & Somente a percepção da qualidade de vida dos participantes & 3 \\
\hline c & Variáveis fisicas e qualidade de vida & 2 \\
\hline d & Condições de vida e saúde dos sujeitos & 1 \\
\hline
\end{tabular}

Os 13 estudos da primeira tendência e os dois da terceira tiveram como objetivo comum analisar os efeitos de um programa de exercícios sistematizados sobre determinadas variáveis físicas (antropométricas, metabólicas e hemodinâmicas), nas quais observamos abordagens centradas, apenas, em parâmetros biológicos do organismo humano.

Nesses estudos, os dados foram obtidos por meio de medições e testes físicos, sendo as medidas antropométricas executadas em quase todos: massa corporal (12 estudos), estatura (11), dobras cutâneas (7) e perímetros, principalmente da cintura (8). Os testes físicos mais aplicados foram: aptidão cardiorrespiratória; resistência muscular/força e flexibilidade. Foram realizados também exames laboratoriais: coleta de sangue (8), urina (2) e dosagem de hormônios (1). Foi aferida a pressão arterial (8), a frequência cardíaca (7) e feitos exames clínicos, como eletrocardiograma (4).

Nove estudos realizaram anamnese/entrevista inicial antes da realização dos testes, para obter dados pessoais, hábitos alimentares e de vida, histórico de doença individual e familiar e condição física, bus- 
cando diagnosticar se cada sujeito estava apto para participar e se era portador de algum fator que pudesse alterar os resultados. Em alguns estudos, a anamnese também contou com avaliações clínicas realizadas por médicos ginecologistas (2); cardiologistas (2) e em uma não foi mencionada a especialidade.

Observamos que os testes físicos foram realizados e o programa de exercícios foi avaliado com ênfase na dimensão física, uma vez que os resultados foram apresentados e explicados a partir da anatomia e da fisiologia. Notamos a desconsideração de aspectos relacionados à subjetividade e às condições de existência dos pesquisados. As modificações ou invariâncias de aspectos anatomofisiológicos foram desvinculadas do viver das pessoas de meia idade, que envolvem elementos como sua história e condições de vida, o trabalho, a família ou suas perspectivas existenciais.

Os estudos relacionados à qualidade de vida (5) objetivaram analisar os efeitos de um programa de exercícios sobre a percepção dessa variável nos indivíduos. O conceito de qualidade de vida proposto por Nahas (2003, p. 14) tem sido tomado por referência: "condição humana resultante de um conjunto de parâmetros individuais e sócioambientais, modificáveis ou não, que caracterizam as condições em que vive o ser humano". Os estudos abordaram o corpo humano para além do funcionamento orgânico, buscando estudar os efeitos dos exercícios em outras esferas da vida, sendo usado o termo "domínios" para se referir a outras dimensões humanas, tais como: domínios "físico, psicológico, relações sociais e meio ambiente" (ZANCHETTA, 2006; OLIVEIRA, 2008; PASETTI, 2005) ou "emocional, físico e social" (BENETTI, 1999) ou "capacidade funcional, bem-estar, faltas e/ou dificuldades no trabalho, dor, fadiga, rigidez, sono, ansiedade e depressão" (KONRAD, 2005). Para isso, utilizaram instrumentos de coleta de dados como o WHOQOL-Bref ${ }^{3}$ (3), sendo em uma pesquisa aplicado juntamente com o histórico tabagístico e o teste de Fragestrom. As outras pesquisas usaram o $\mathrm{FIQ}^{4}$, o $\mathrm{PSQI}^{5}$, um questionário sócio-demográfico e clínico, e o MacNew QLMI ${ }^{6}$.

\footnotetext{
3-World Health Organization Quality of Life.

4-Fibromyalgia Impact Questionnaire.

5-Pittsburgh Sleep Quality Index.

6-Questionário de Qualidade de Vida Infarto do Miocárdio.
} 
Nos estudos da terceira tendência, os quais avaliaram variáveis físicas e qualidade de vida, observamos a predominância das variáveis físicas, caso de Benetti (1999), a qual dedicou 25 páginas para tratar das variáveis físicas e três para qualidade de vida.

Nas três primeiras tendências identificamos que a lógica geral foi a de pré-teste/intervenção/pós-teste, caracterizando uma hegemonia de pesquisas experimentais ou quase-experimentais. As relações de causalidade configuraram-se como do tipo "externa explicativa" (BRUYNE; HERMAN; SCHOUTTETE, 1991), indicando que os estudos consideraram os resultados obtidos nessas avaliações como fruto do programa de exercícios, numa relação direta entre causa e efeito. Tal relação de causalidade apresentou-se na forma simplificada e descontextualizada com a qual os autores justificaram a existência ou a constituição dos fenômenos estudados.

Os programas de exercícios propostos prolongaram-se de um dia a doze meses e aconteceram de uma a cinco vezes por semana, com duração de 40 a 90 minutos por sessão. Apesar de grande parte das intervenções contar com ao menos um encontro semanal entre participantes e professor/pesquisador durante meses, nenhuma pesquisa da primeira tendência apresentou qualquer tipo de informação referente à vida dos sujeitos, mencionando só dados fisiológicos.

Benetti (1999, p.71) objetivou comparar a eficácia de três tipos de tratamento sobre os fatores de risco e a qualidade de vida relacionada à saúde em pacientes coronariopatas pós infarto agudo do miocárdio e constatou: "podemos observar que no grupo I, um maior número de sujeitos abandonaram o fumo $(n=6)$ em comparação com o GII e GI$\mathrm{II}^{7 "}$. Segundo o autor, o abandono do fumo foi resultado do programa proposto, mas a ausência de outras informações deixou margem para questionamentos acerca da validade interna, considerando a possível influência de outros fatores na tomada de decisão.

Em alguns estudos da primeira e terceira tendências houve preocupação com o controle dos fatores externos ou variáveis no momento da realização das avaliações. Foram citadas tentativas de controle da alimentação, temperatura do ambiente, prática de outros exercícios antes da realização dos testes, por exemplo, verificando se "as condi-

7-O grupo I foi submetido a tratamento clínico mais programa de reabilitação cardíaca com exercícios regulares; o II foi submetido a tratamento clínico mais atividade física espontânea e o III apenas a tratamento clínico. 
ções das voluntárias eram satisfatórias para a realização dos mesmos, se tinham dormido bem nas noites anteriores, se estavam tranqüilas, sem preocupações, etc." (OLIVEIRA, 2005, p.35). Destarte, identificamos a tentativa de isolar os fenômenos estudados. Percebemos que as únicas oportunidades dos sujeitos para manifestar sentimentos/opiniões eram as anamneses ou os questionários, nas quais tinham a oportunidade de expressar/falar/escrever sobre diferentes aspectos das suas vidas. Importante destacar, entretanto, conforme mostram os apêndices, que tanto as anamneses quanto os questionários utilizados apresentaram perguntas fechadas com questões de múltipla escolha ou respostas em escalas, o que limitou a expressão dos sujeitos acerca de dados potencialmente relevantes.

Entendemos que uma pergunta faz parte de um instrumento aplicado em uma pesquisa por ser importante. Partindo desse pressuposto, pensamos que a resposta deva ser a mais fiel possível à realidade dos sujeitos e ser considerada pelo pesquisador a fim de obter resultados mais fidedignos. Nesse sentido, interpretamos que houve certa limitação proveniente, especialmente, do cerceamento das possibilidades de resposta pelos sujeitos inquiridos pelo formato de múltipla escolha ou escala.

Avaliamos que algumas questões não podem ser apreendidas via questionário fechado, como é o caso das seguintes perguntas pertencentes ao WHOQOL-Bref: "Em que medida você acha que sua vida tem sentido?", "Você tem energia suficiente para seu dia-a-dia?", "Quão satisfeito(a) você está com a sua saúde?". Questionar um sujeito sobre o sentido de sua vida e dar a ele apenas as opções de resposta: "nada, muito pouco, mais ou menos, bastante, extremamente" nos parece simplista, podendo conduzir a um falseamento da realidade. Para apreender concepções de saúde se faz importante considerar sua construção como derivada de um conjunto de modos e costumes de um tempo histórico e de instituições que atuam de forma importante no cotidiano (DALBEN; SOARES, 2008); tal consideração não foi identificada nos estudos em tela.

Este tipo de prática científica parece expressar certo reducionismo em curso na ciência moderna, fundada na racionalidade instrumental, com o fetichismo da técnica suplantando a proximidade do real da vida dos sujeitos. As questões de método denotam certa ausência de auto-reflexão e incapacidade de compreensão de suas próprias questões filosóficas, tanto na ética quanto na epistemologia, conforme alerta 
Horkheimer (2002, p. 86): “está bem dentro da linha das ideias do positivismo reduzir o que lhe escapa como 'valores' a fatos, e representar as coisas do espírito como algo reificado, um tipo de mercadoria ou fato cultural especial".

A título de exemplo, problematizamos a seguinte questão do FIQ: "durante a última semana, em quantos dias você se sentiu bem?" (opções de resposta: "escala de 0 a 7"). Nos resultados de Konrad (2005, p.52) encontramos a seguinte análise :

A percepção do bem-estar tem sido utilizada como parte dos indicadores de qualidade de vida. O bem-estar é avaliado no FIQ por meio do número de dias em que as pessoas referiram sentirse bem, ou seja, sem a presença exacerbada de sintomas. Este componente apresentou um valor médio de $6,3(\mathrm{SP}=3,9)$ em uma escala que variava de 0 a 10 , mostrando ser um item bastante afetado pelos sintomas da SFM, visto que, em pelo menos três dias da semana as mulheres relataram não se sentirem bem.

A partir desse texto pudemos perceber três pontos coincidentes com outros estudos: quantificação das informações, homogeneização dos sujeitos e estreitamento do foco.

A forte tendência de quantificação das informações mostrou-se evidente nos instrumentos selecionados, pois as informações foram transformadas em um modelo numérico. No caso das medidas e testes físicos, a quantificação foi obtida de maneira direta, uma vez que o resultado de ambos geralmente aparecia na forma quantitativa (ex.: massa corporal $=50 \mathrm{~kg}$ ). No caso da percepção da qualidade de vida, os dados eram subjetivos, mas também foram enquadrados quantitativamente (ex.: muito insatisfeito $=1$ ).

Bagrichevsky e Estevão (2005, p.12) também criticam o emprego mundial de inquéritos para mensurar qualidade de vida, "o que já é, no mínimo, um paradoxo linguístico", e indicam como significativo o direcionamento à operacionalização desse conceito em saúde, ao invés da exploração de outras possíveis interfaces metodológicas que tangenciem melhor a realidade.

As análises de dados corroboraram com essa tendência. Verificamos que, das 19 pesquisas analisadas, 17 utilizaram a estatística como 
ferramenta para tratamento dos dados, na forma de estatística descritiva e/ou testes estatísticos ${ }^{8}$, com auxílio de softwares 9 .

Benetti (1999, p.59) exemplificou uma situação de primazia da quantificação. O pesquisador deixou de tratar um aspecto que poderia contribuir com os seus objetivos:

[...] os níveis de escolaridade encontrados nos 3 grupos mostraram que o grupo I foi superior aos grupos II e III e que o grupo III foi superior ao grupo II. Desta forma, valores diferentes encontrados para escolaridade, entre os grupos, particularmente entre I e II, constituíram um aspecto limitante deste estudo, uma vez que não foi possível incluir este item como fator de pareamento entre os grupos.

Entendemos que a presença da escolaridade no questionário é indicativo de sua importância, por isso causou estranheza o fato de a mesma não ter sido analisada por não se adequar a um padrão codificado. Esta pesquisa avaliou três grupos, sendo o I formado por pacientes de uma clínica particular de reabilitação cardiopulmonar e metabólica e realizou tratamento clínico mais exercícios sistematizados; os grupos II e III foram formados por pacientes de um hospital público, o II realizou tratamento clínico mais exercícios espontâneos não orientados e o III só realizou tratamento clínico. Os resultados indicaram que o grupo I foi o único que "atingiu uma das metas principais no tratamento da DAC: eliminar o maior número possível de fatores de risco" (BENETTI, 1999, p.88). Verificamos que este tratamento só está acessível para minoria da população com poder aquisitivo para frequentar um estabelecimento particular, além de ser este mesmo grupo o que possuía maior nível de escolaridade. Na soma destas informações inferimos que o grupo I obteve melhores resulta-

8-Por exemplo: para verificar a normalidade dos dados: Kolmogorov-Smirov, Lilliefors e Mauchley; para comparar médias: anova one e/ou two-way e teste $t$ de student (paramétricos); teste de Wilcoxon, de Mann-Whitney, Kruskall-Wallis e Friedman (não-paramétricos); para comparar frequências: qui-quadrado, regressão binária e teste de Fischer; para estabelecer correlação entre uma ou mais variáveis: correlação de Pearson (paramétrica) e de Spearman (não-paramétrica), regressão linear, correlação canônica, effect-size, e análise multivariada.

9-Sendo mais citado o Excel, SPSS, Statistica, S-Plus, entre outros.

Pensar a Prática, Goiânia, v. 16, n. 3, p. 619-955, jul./set. 2013 
dos não só por realizar exercícios orientados, mas porque possuía melhores condições de vida, dado central não analisado.

A necessidade de instrumentalizar/enquadrar todos os tipos de informação em um padrão numérico foi expressiva na produção estudada. A matemática é o instrumento clássico da razão formalizada, que a exulta por considerá-la clara, imperturbável e auto-suficiente, aquilo que a qualidade do humano certamente não é (HORKHEIMER, 2002). Segundo este autor,

[...] assim que um pensamento ou uma palavra se torna um instrumento, podemos nos dispensar de 'pensar' realmente isso, isto é, de examinar detidamente os atos lógicos envolvidos na formulação verbal desse pensamento ou palavra. Como já se tem afirmado, com frequência e corretamente, a vantagem da matemática - o modelo de todo o pensamento neopositivista reside justamente nesta "economia intelectual" (HORKHEIMER, 2002, p.28).

O problema não está na quantificação, a questão é que as informações obtidas pela sua via precisariam ser reincorporadas à totalidade, a uma análise que levasse em conta aspectos subjetivos, micro e macrossociais, para poderem ter algum sentido na vida das pessoas.

Horkheimer (2002, p.84) reconhece o potencial de contribuição da filosofia positivista, ao dizer que esta "poderia, de fato, servir de excelente começo para o pensamento dialético". Destacamos um anseio que se fez presente na leitura de algumas teses e dissertações, uma espécie de expectativa não atendida ou o despertar de questões que não foram debatidas. Foi preciso lembrar que a intenção de discussão filosófica não fazia parte da perspectiva adotada e do alerta de Horkheimer $(2002 ; 1990)$, reconhecendo que ao considerar servir ao pensamento dialético, é exatamente nesse ponto que termina a filosofia positivista.

A homogeneização, por sua vez, refere-se ao fato de uma pergunta pressupor que todos os sujeitos sentem algo na mesma intensidade. Isto fica evidente não quando o sujeito responde, mas na análise dos dados. Quando o sujeito responde: "em quantos dias você se sentiu bem?", ele o faz conforme sua perspectiva particular e admite-se que o sentir-se bem para um não precisa ser igual para outro. No entanto, ao fazer a análise, o procedimento homogeneíza as sensações ao unir 
indiscriminadamente as respostas, codificando os dados e expressando-os por meio da média.

Dentro da organização interna, percebemos uma espécie de dissolução gradativa da identidade dos sujeitos durante a pesquisa. Em alguns casos, observamos na introdução e na revisão de literatura uma perspectiva além da anatomofisiológica; na metodologia uma redução do olhar do pesquisador, mas ainda cada sujeito estava presente, ao passar pelas avaliações; nos resultados, as subjetividades deram lugar à média, a qual pode representar nenhum sujeito.

O estreitamento do foco identificado nesses estudos diz respeito ao fato de a pergunta ser plural, mas as respostas serem específicas. A pergunta que estamos problematizando em nosso exemplo expressa sentir-se bem, mas a resposta pode não se referir necessariamente à busca do pesquisador que objetiva conhecer a relação do bem-estar com a fibromialgia, nesse caso. A pessoa pode sentir-se bem por outros motivos, não relacionados com a ausência de dores ou sintomas da doença. O sentimento não é algo linear e pode ser difícil categorizá-lo no cotidiano como proveniente disto ou daquilo.

A resposta a um questionário fechado tende a trazer dados bastante reduzidos frente a realidade daqueles sujeitos a que se refere. Informações mais amplas poderiam ser melhor apreendidas a partir de entrevistas, onde a presença atenta do pesquisador à fala e à gestualidade do sujeito permitiria alcançar uma maior aproximação, além da possibilidade de tirar dúvidas, detalhando respostas insuficientes.

Admitimos que a complexidade do real é inapreensível ao processo de pesquisa. Compreendemos também, que nenhum instrumento de pesquisa consegue colher dados suficientes para analisar ou compreender os sujeitos em sua condição de vida. A atividade científica, porém, deveria fazer um esforço por manter coerência entre as técnicas e instrumentos com a natureza dos elementos vitais que busca analisar. Deveria buscar, também, estabelecer nexos entre esses elementos constituintes da totalidade, indo além das aparências e não superficializando a análise, sob o argumento da complexidade ou do desconhecimento da mesma.

A escolha por questionário fechado como instrumento privilegiado parece ser decorrente da preocupação com critérios de validade científica. Nesses estudos, os pesquisadores escolheram instrumentos de pesquisa reconhecidos cientificamente, importados de outros países e validados para a população brasileira, apesar das críticas que vêm so- 
frendo. Seus valores tem sido considerados adequados para os índices de validade e reprodutibilidade, contribuindo para a comparação com dados de outras localidades e populações. Konrad (2005, p.37), referindo-se ao FIQ e PSQI, afirmou: "para que estes dois instrumentos pudessem ser utilizados neste estudo, ambos passaram por um processo de tradução e validade".

Para ampliar a reflexão sobre essa temática, lembramos os estudos apresentados por Canguilhem (1995), os quais foram realizados com diferentes povos e apontaram funcionamentos fisiológicos diversos em grupos com normas de vida diferentes. Os dados indicam que a relação com o meio - cultural e natural - constroi modos de funcionamento dos processos orgânicos de formas diferenciadas, tornando questionável a validação dos instrumentos em contextos distintos, assim como a generalização dos resultados.

As escolhas metodológicas da primeira, segunda e terceira tendências relacionaram-se com alguns critérios de validação científica. $\mathrm{O}$ principal foi o uso da análise estatística dos dados, critério praticamente exclusivo para consideração do que era verdadeiro ou científico. Foram frequentes os usos generalizados de verificação do grau de significância estatística, além da presença de instrumentos validados nacional e/ou internacionalmente e com fidedignidade reconhecidas cientificamente.

Observamos no material empírico a predominância da descrição em detrimento de análises críticas, apontando para uma contemplação do estado atual das coisas e não uma perspectiva de alteração. Tal característica não causaria estranhamento se as pesquisas não apresentassem objetivos voltados a aplicabilidade social de seus resultados.

Dezoito pesquisas expuseram seus resultados dentro da seguinte lógica: descreveram os dados estatísticos, compararam os resultados encontrados entre grupos e/ou dentro do mesmo grupo, verificando se houveram correlações "estatisticamente significativas" nas variáveis antes/depois do programa de exercícios proposto. A discussão dos dados consistiu, basicamente, na comparação do que foi evidenciado na pesquisa com outros estudos realizados com populações semelhantes ou que abordaram as mesmas variáveis. Interpretamos que a pouca frequência de críticas esteve associada à intenção de neutralidade e imparcialidade dos pesquisadores, talvez, resquícios de uma concepção de ciência pura. 
De maneira geral, percebemos que os pesquisadores afastaram-se de seus objetos de pesquisa e estabeleceram com os mesmos uma relação mecânica, replicando estudos anteriores e buscando garantir a objetividade do estudo. Isso porque os objetos apareceram recortados da realidade da qual faziam parte e isolados de outras relações que the conferiam sentido. Assim, parece ter predominado uma visão mecanicista de ser humano como portador de variáveis controladas e controláveis.

Ao buscarem a imparcialidade na prática científica, os pesquisadores desconsideraram que as escolhas que orientaram suas pesquisas e as tomadas de decisão foram direcionadas pelos seus interesses, por determinantes históricos, pelo conhecimento acumulado a partir de experiências de vida diversas, pela sua visão de mundo; um "absolutismo ingênuo", como avalia Horkheimer (2002, p.84).

Os critérios de cientificidade apresentados pelas pesquisas analisadas se basearam na sequência de procedimentos exigidos pelo método convencional de ciência, o qual se restringiu a um caráter técnico-instrumental. Na maioria dos estudos ficou explícito que não importava a realidade em si, mas a realidade captada pelo método, sendo esta considerada cientificamente verdadeira, como também substitutiva do real, especialmente nas conclusões e recomendações. Observa-se, assim, uma concepção de realidade que se apresenta como fragmentada, estática e aistórica, coincidindo apenas com o momento da pesquisa.

Diante das evidências do material analisado (tendências a, b, c), identificamos que a abordagem epistemológica dos estudos aproximou-se da tendência empírico-analítica. Um único estudo mostrou-se desvinculado deste paradigma epistemológico, apresentando uma abordagem crítico-dialética, pautada no materialismo histórico-dialético (tendência d).

É o caso do estudo de Martinez (2007) que se colocou como um contraponto às demais pesquisas analisadas. Além de estudar os efeitos de um programa de práticas corporais sobre determinados aspectos, objetivou analisar as condições de vida e saúde de bancários e os fundamentos que embasam a proposta hegemônica de uma prática corporal no mundo do trabalho, a ginástica laboral.

Os dados foram coletados por entrevistas semi-estruturadas, observações/diário de campo, análise documental e tratados por meio da análise de conteúdo. A avaliação do programa de práticas corporais foi realizada mediante análise do discurso dos sujeitos, os quais relataram 
suas sensações e percepções na participação em aulas de yoga, a partir de ações realizadas pelo Sindicato dos Bancários. Os resultados foram apresentados de forma que teoria, empiria e cotidiano mostravam-se em constante tensão.

A pesquisadora buscou relacionar as condições de vida e trabalho nos bancos para compreender o processo saúde-doença. Os trabalhadores foram concebidos como integrantes de um contexto social, o qual "envolve desde os processos mais amplos da estrutura políticoideológica da sociedade, até os processos particulares de uma classe ou grupo, bem como a quotidianeidade familiar e pessoal" (MARTINEZ, 2007, p.16).

Identificamos que as causas dos fenômenos foram explicadas a partir da inter-relação entre as partes (os próprios fenômenos) e o todo, que se articularam especialmente pelo princípio da contradição ou luta de contrários. Foram abordadas

as principais mudanças provocadas pela reestruturação produtiva e suas implicações no processo saúde-doença dos trabalhadores, situando o grave problema de adoecimento por LER, transtornos mentais, exigência de multi-qualificações dos trabalhadores e as novas formas de controle e dominação do trabalho (MARTINEZ, 2007, p.17).

Foi feita a contextualização do trabalho bancário e sua relação com a vida e saúde dos trabalhadores e a Educação Física foi concebida como uma via de comunicação com a realidade, a partir do questionamento dos princípios da ginástica laboral e da tensão com a intervenção proposta pela pesquisadora baseada em outros pressupostos teórico-metodológicos e objetivos que se opõem a práticas hegemônicas.

As críticas vieram acompanhadas de propostas de superação de aspectos que foram apontados como problemáticos no decorrer da argumentação. Esta proposta não se ateve à abstração (no sentido de um idealismo utópico, baseado na mudança articulada à ideia de que o conhecimento da realidade, pela investigação científica, pode mudála), mas vinculou-se às condições concretas dos sujeitos, entendidos como parte do contexto social. A pesquisa buscou apresentar uma concepção de realidade em movimento e histórica, onde o objeto compunha um fato histórico, o qual poderia ser modificado. 
Os critérios de validação científica tiveram como suporte: a análise qualitativa, na intenção de compreender a complexidade do objeto; a análise dos dados pelo método da hermenêutica-dialética; e o referencial teórico adotado. Percebemos que a ciência foi entendida como uma atividade, produto da ação humana que visa à produção de conhecimento para a superação de aspectos estabelecidos na realidade.

\title{
Considerações finais:
}

A partir da análise das 19 pesquisas, identificamos a predominância da perspectiva empírico-analítica em estudos com pessoas na meia idade. Evidenciamos que o trato com os sujeitos apresentou uma supremacia da tecno-ciência em detrimento do humano e do social. Os métodos enfatizaram a quantificação referente à vida dos sujeitos, desprezando explicações mais qualitativas, sejam de âmbito social ou subjetivo, secundarizando a perspectiva humana na pesquisa.

Destarte, o desafio central que se apresenta para o campo acadêmico da Educação Física parece se colocar no plano de compreender o sujeito adequadamente na produção científica que problematiza os fenômenos humanos em sociedade. Caberia ao pesquisador colocar-se na intersecção entre a aproximação/distanciamento do sujeito, de maneira a ajustar o foco do olhar e a apreender os dados quantitativos como aspectos da realidade, os quais só tem sentido quando complementados por dados qualitativos, devolvendo seu sentido a realidade dos sujeitos envolvidos. Significaria, assim, compreender a necessidade de superar a hegemonia do olhar do pesquisador para dentro e de longe, de forma que a pesquisa se aproxime e auxilie na compreensão do real, pois se os discursos apresentados hegemonicamente foram monolíticos, impessoais e homogeneizantes, a vida das pessoas de meia idade é plural e corporalmente imbricada com a realidade de estar no mundo.

THE MATHEMATIZATION OF LIFE: ANALYZE OF SCIENTIFIC PRODUCTIONS OF THE PHYSICAL EDUCATION FIELD ABOUT THE MIDDLE AGE PERSON'S

\begin{abstract}
This text aims to analyze the methodological organization that structure researches from Stricto Sensu Post Graduate programs from Physical Education with middle aged people ant theirs implications on the knowledge production face to concrete
\end{abstract}


social reality. We analyzed data from two thesis and seventeen essays based on the quadrupole type. It was identified eighteen researches that was near of the empirical-analytical epistemological current, and one with the critical-dialectic references. The method questions emphasized the quantification of information related to subjects lives, despising explications from qualitative orders, in the social and subjective scope, what, sometimes distanced the studies of real plan, in the sense of a potential significant social impact.

Keywords: Physical Education and Training. Middle age. Motor Activity. Research Report.

\section{LA MATEMATIZACIÒN DE LA VIDA: UN ANALISIS DE LAS PRODUC- CIONES CIENTÍFICAS DEL CAMPO DE LA EDUCACIÒN FİSICA SO- BRE LAS PERSONAS DE MEDIANA EDAD}

\section{Resumen}

El Objetivo fue analizar las organizaciones metodológicas que estructuran las investigaciones en el campo de la Educación Física con personas de mediana edad y sus implicaciones en la producción del conocimiento de cara a la realidad social concreta. Se analizaran los datos de dos tesis y diecisiete disertaciones de master con base en modelo cuádruplo. Identificamos que dieciocho investigaciones se acercan de la tendencia epistemológica empírico analítica e una del marco analítico crítico dialéctico. Las cuestiones de método indican una fuerte tendencia a la cuantificación de las informaciones acerca de la vida de los sujetos, haciendo caso omiso de las explicaciones de carácter más cualitativo en ámbito social o subjetivo, lo que por veces distanció los estudios del plano del real, en el sentido de un potencial impacto social significativo.

Palabras clave: Educación y Entrenamiento Físico. Mediana Edad. Actividad Motora. Informe de Investigación.

\section{Referências}

BAGRICHEVSKI, M.; ESTEVÃO, A. Os sentidos da saúde e a Educação Física: apontamentos preliminares. Revista Arquivos em Movimento, Rio de Janeiro, v.1, n.1, p.65-74, jan./jun., 2005.

BANKOFF, A. D. P. et al. Um olhar acerca da produção do conhecimento na área da ciência do esporte: tendências e perspectivas. Revista Brasileira de Ciências do Esporte, Campinas, v. 24, n. 3, p. 195-207, maio, 2003.

BENETTI, M. Alterações de fatores de risco e qualidade de vida em pacientes coronarianos acometidos de infarto agudo do miocárdio, submetidos a diferentes tipos de treinamento. $1999.158 \mathrm{f}$. Dissertação (Mestrado em Educação Física)-Centro de Desportos, 
Programa de Pós-Graduação em Educação Física, Universidade Federal de Santa Catarina, Florianópolis, 1999.

BRANDÃO, C. F.. Considerações sobre a qualidade da produção científica da educação física brasileira. Revista Brasileira de Ciências do Esporte. Campinas, v. 21, n. 2/3, p. 103-107, jan./maio, 2000.

BRUYNe, P.; HERMAN, J.; SCHOUTTETE, M. Dinâmica da Pesquisa em Ciências Sociais. Tradução Ruth Joffily. 5. ed. Rio de Janeiro: Francisco Alves, 1991.

CANGUILHEM, G. O normal e o patológico. Tradução Maria Thereza Redig de Carvalho Barrocas e Luiz Octavio Ferreira Barreto Leite. 4. ed. Rio de Janeiro: Forense Universitária, 1995.

DALBEN, A.; SOARES, C. L. A revista vida e saúde: modos de olhar e educar o corpo feminino em suas páginas (1940-1950). Revista Pensar a Prática, Goiânia, v. 11, n. 3, p.239-250, set./dez., 2008.

DOMINGUES, J. Gerações, modernidade e subjetividade coletiva. Tempo social, v. 14, n. 1, p. 67-89, maio, 2002.

DUARTE, C. P.; SANTOS, C. L.; GONÇALVES, A. K. A concepção de pessoas de meia idade sobre saúde, envelhecimento e atividade física como motivação para comportamentos ativos. Revista Brasileira de Ciências do Esporte, v. 23, n. 3, p. 35-48, maio, 2002.

FERON, A.; SILVA, M. M. A igreja do "diabo" e a produção do conhecimento na educação física. Revista Brasileira de Ciências do Esporte, Campinas, v. 29, n. 1, p. 107-122, set., 2007.

FRIZZO, G. F. E. A produção do conhecimento da educação física no programa de pós-graduação em ciências do movimento humano da UFRGS. Pensar a Prática, Goiânia, v. 13, n. 3, p. 1-16, set./dez., 2010.

GAMBOA, S. Pesquisa em Educação: métodos e epistemologias. Chapecó: Argos, 2007.

GONÇALVES, A. K.; DUARTE, C. P.; SANTOS, C. L. Atividade física na fase da meia idade: motivos de adesão e de continuidade. Revista Movimento, Porto Alegre, v. 7, n. 15, p.75-88, 2001. 
HORKHEIMER, M. Eclipse da razão. Tradução Sebastião Uchoa Leite. São Paulo: Centauro, 2002.

. Teoria crítica: uma documentação. Tomo I. São Paulo: Perspectiva, EDUSP, 1990.

KONRAD, L. Efeito agudo do exercício físico sobre a qualidade de vida de mulheres com síndrome da fibromialgia. 2005. Dissertação (Mestrado em Educação Física Centro de Desportos, Programa de Pós-Graduação em Educação Física, Universidade Federal de Santa Catarina, Florianópolis, 2005.

LAVILLE, C.; DIONNE, Y. A construção do saber: manual de metodologia da pesquisa em ciências humanas. Belo Horizonte: UFMG, 1999.

LEMOS, E. M. de B. C. Formação, pesquisa e pós-graduação em educação física: um recorte dos 30 anos de educação física na UEPB. Holos, v. 25, n. 1, pp. 17-23, 2009.

LESSARD-HÉBERT, M.; GOYETTE, G.; BOUTIN, G. Investigação qualitativa: fundamentos e práticas. 2. ed. Tradução Maria João Reis. São Paulo: Instituto Piaget, 2005.

LÜDORF, S. M. A. Panorama da pesquisa em educação física da década de 90: análise dos resumos de dissertações e teses. Revista da Educação Física/UEM. Maringá, v. 13, n. 2, p. 19-25, jul./dez., 2002.

MARTINEZ, J. Superações da Educação (Física) bancária pela Saúde Coletiva: pesquisa-ação no sindicato de Florianópolis. 2007. 126 f. Dissertação (Mestrado em Educação Física)-Centro de Desportos, Programa de Pós-Graduação em Educação Física, Universidade Federal de Santa Catarina, Florianópolis, 2007.

MENEZES, A. Efeitos de um programa de exercícios físicos estruturados nos componentes da síndrome metabólica. 2004. 105 f. Dissertação (Mestrado em Educação Física)-Centro de Desportos, Programa de Pós-Graduação em Educação Física, Universidade Federal de Santa Catarina, Florianópolis, 2004. 
MOLINA NETO, V. et al. Reflexões sobre a produção do conhecimento em Educação Física e Ciências do Esporte. Revista Brasileira de Ciências do Esporte. Campinas, v.28, n. 1, p.145-165, set., 2006.

MORAES, C. Efeito do exercício aeróbio sobre os níveis séricos de leptina em mulheres obesas. 2004. 70 f. Dissertação (Mestrado em Ciências da Motricidade)-Instituto de Biociências, Universidade Estadual de São Paulo, Rio Claro, 2004.

NAHAS, M. V. Atividade física, saúde e qualidade de vida. Londrina: Midiograf, 2003.

NÓBREGA, T. P. et al. Educação física e epistemologia: a produção do conhecimento nos congressos brasileiros de ciências do esporte. Revista Brasileira de Ciências do Esporte, Campinas, v. 24, n. 2, p.173-185, jan., 2003.

OLIVEIRA, J. Avaliação da qualidade de vida de um grupo de tabagistas participantes de um programa interdisciplinar em Centro de Saúde. 2008. 94 f. Dissertação (Mestrado em Educação Física)-Faculdade de Educação Física, Universidade Estadual de Campinas, Campinas, 2008.

OLIVEIRA, M. K. Ciclos de vida: algumas questões sobre a psicologia do adulto. Educação e Pesquisa, v. 30, n. 2, p. 211-229, 2004.

OLIVEIRA, V. Análise da variabilidade da frequência cardíaca em mulheres na pós-menopausa sedentárias e treinadas. 2005. Dissertação (Mestrado em Educação Física)-Faculdade de Educação Física, Universidade Estadual de Campinas, Campinas, 2005.

PASETTI, S. Deep Water Running para redução da gordura corporal em mulheres na meia idade: estudo de intervenção em Campinas-SP. 2005. 121 f. Dissertação (Mestrado em Educação Física)-Faculdade de Educação Física, Universidade Estadual de Campinas, Campinas, 2005.

SACARDO, M. S. Estudo bibliométrico e epistemológico da produção científica em Educação Física na Região Centro-Oeste do Brasil. 2013. 255 f. Tese (Doutorado em Educação) -Universidade Federal de São Carlos, São Carlos, 2013. 
SANTOS, S.; KNIJNIK, J. Motivos de adesão à prática de atividade física na vida adulta intermediária. Revista Mackenzie de Educação Física e Esporte, São Paulo, v. 5, n. 1, p. 23-34, 2006.

SANTOS, F. C.: DAMICO, J. G. S. O mal-estar na velhice como construção social. Pensar a Prática, Goiânia, v. 12, n. 1, p. 01-09, 2009.

SILVA, R. Mestrados em Educação Física no Brasil: pesquisando suas pesquisas. Santa Maria. Dissertação (Mestrado em Educação Física). UFSM, Santa Maria, 1990.

. Pesquisa em Educação Física: determinações históricas e implicações epistemológicas. 1997. Tese (Doutorado em Educação)Faculdade de Educação Física. Universidade Estadual de Campinas, Campinas, 1997.

SOUSA, F. O que é "ser adulto"? As práticas e representações sociais - A Sociologia do Adulto. In: CONGRESSO PORTUGUẾS DE SOCIOLOGIA, 6., 2008, Lisboa. Anais... Lisboa: [s. n.], 2008.

. O que é "ser adulto"? As velhas e novas representações sociais sobre o que é ser adulto. CONGRESSO PORTUGUÊS DE SOCIOLOGIA, 6., 2004, Braga. Anais... Braga: [s. n.] 2004.

THE LANCET. What is the purpose of medical research? The Lancet, v. 381, n. 9864, p. 347, feb., 2013.

ZANCHETTA, L. Avaliação subjetiva da qualidade de vida em indivíduos de meia idade submetidos a treinamento físico. 2006. Dissertação (Mestrado em Educação Física)-Faculdade de Educação Física, Universidade Estadual de Campinas, Campinas, 2006.

Recebido em: 10/07/2013

Revisado em: 29/08/2013

Aprovado em: 10/10/2013

Endereço para correspondência

pri2602@hotmail.com

Priscilla de Cesaro Antunes

Universidade Federal de Goiás

Faculdade de Educação Física - Campus Samambaia

Caixa Postal 131 -CEP: 74001-970 Goiânia - Goiás

Pensar a Prática, Goiânia, v. 16, n. 3, p. 619-955, jul./set. 2013 